\title{
Analysis of the effect on steam turbine rotor of load variation for Cogeneration Steam Turbine
}

\author{
Zheming Song ${ }^{a}$, Yongsheng $\mathrm{Su}^{\mathrm{b}}$ \\ East China University of Science and Technology, Shanghai 200000, China \\ asongzheming1@163.com, byssu@ecust.edu.cn
}

Keywords: cogeneration steam turbine, thermoelectric load, back pressure, rotor.

\begin{abstract}
For the cogeneration steam turbine, due to the thermoelectric load changes frequently, which will cause the back pressure instability, and cause sharp fluctuations in temperature and pressure inside the turbine, these fluctuations will affect the normal work of the turbine rotor, even some mechanical fault. In order to find out the cogeneration steam turbine running at full load, the influence of the thermoelectric load changes to the turbine rotor, analyzed under different thermoelectric load conditions, the trend of the back pressure, and analysis of the temperature and pressure's change in the steam turbine brought about by the back pressure's change as well as the impact of these changes in temperature and pressure brought to the turbine rotor. The conclusion that due to the thermoelectric load's change will cause the turbine rotor thermal bending and axial thrust imbalance.
\end{abstract}

\section{Introduction}

Both the development of the economy and the progress of the society, must be based on modern high degree of electrification. Electric power industry is one of the basic industries of modern country, the electric power production is also one of the important indicators for a country's level of economic development. In modern power industry, thermal power's quantity is the largest, followed by hydropower and nuclear power. In the thermal power plant and nuclear power station, the electricity is major produced through steam turbine driven generator, steam turbine is an important powered mechanical equipment for modern countries [1].

Steam turbine is a rotary machinery which can transfer steam heat energy into mechanical energy. It is mainly used as the prime mover to drive the power plant's generator to work. Due to people for the living environment's demands is improve, the living environment is needed to heating, so the cogeneration steam turbine unit in modern power plant has important significance for saving energy [2].

The heating system's load of steam turbine with the season is changing, we always adjust the thermoelectric load ratio in the process when we use steam turbine to produce heat and electricity. But the adjust about the thermoelectric load will have effect on its internal related parameters, and the frequent change and drastic fluctuations on the related parameters will be occured, which have some effects on the steam turbine rotor, then cause some relevant faults about the steam turbine. The supply of electricity and heating will be influenced once the turbine failure, thus affecting the industrial production and the residents normal life.

So this paper is for the cogeneration steam turbine which in the case of full load operation, analyze the trend of its back pressure when the thermoelectric load changes, in addition to analyze the effect on the internal related parameters and the steam turbine rotor which can provides some analysis can learn for future research in related fields.

\section{The operation of cogeneration steam turbine}

The working principle of the cogeneration system. Our common cogeneration system, its working principle is available represents in Fig.1. 


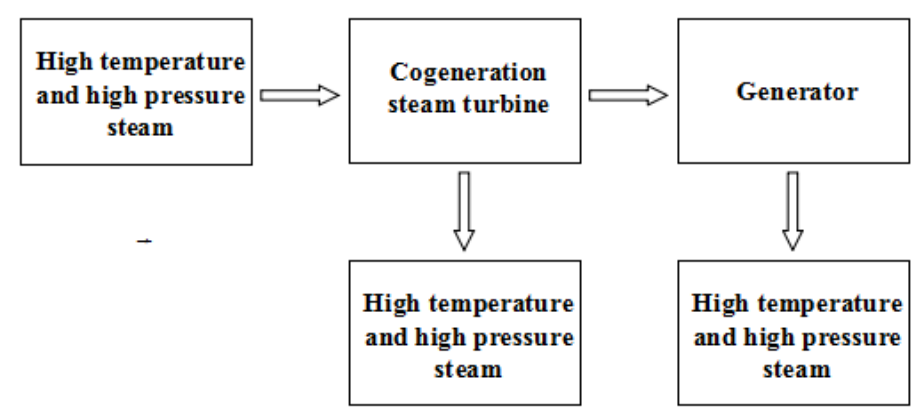

Fig.1 Cogeneration systems work flow chart

From the fig.1, we can see that after the high temperature and high pressure steam into the steam turbine, we can according to the heat users and electricity users demand to adjust the ratio of electricity and extraction steam quantity. So as to reach the purpose of meet the heat users and electricity users demand [3].

The choice of the operating range about back pressure. Back pressure is actually the exhaust pressure at the outlet of the steam turbine, mainly affected by the external load. The back pressure will be changed when the thermoelectric load which in cogeneration system changes. But the back pressure also has a certain operating range, back pressure only in this range, the turbine can normal work.

The operating range about back pressure is related to the conditions of the airflow in the nozzle. For convergent nozzle can be divided into the following three kinds of situation to discuss: ( $P_{c r}$ as the critical pressure, $P_{2}$ as the outlet pressure, $P_{b}$ as the back pressure)

(1) When $P_{b}>P_{c r}, P_{2}=P_{b}>P_{c r}$, the airflow in the nozzle can be fully inflated, this time, reduce the back pressure is can increase flow and velocity of the airflow.

(2) When $P_{b}=P_{c r}, P_{2}=P_{b}=P_{c r}$, the airflow in the nozzle at a critical state, exactly can be fully inflated, this time, the flow and velocity of the airflow reaches the maximum value.

(3) When $P_{b}<P_{c r}, P_{2}=P_{c r}>P_{b}$, the flow and velocity of the airflow is still in the limit state, the airflow will be further inflated when flows through the nozzle. If until to decrease the back pressure in this time, the flow and velocity of the airflow in the nozzle will can't be increased effectively.

It follows that if you want to ensure that the steam turbine can work normally, the best choice of back pressure is $P_{b}=P_{c r}$. At the same time in order to improve the load of steam turbine, the $P_{b}$ is best control close to $P_{c r}$.

Relationship between thermoelectric load and back pressure. Due to the heat users and electricity users demand for heat and electricity is change with the season. So it leads to the thermoelectric ratio be changed when the steam turbine in the case of full load operation. In order to study the trend of the steam turbine back pressure when the thermoelectric load in different states, mainly discussed the back pressure condition when in the following three hypotheses with thermoelectric load state, which can be deduced from the corresponding trend of back pressure when the thermoelectric ratio change.

(1) When the cogeneration steam turbine all heating, without electricity supply, at this time the amount of heating is $Q_{1}$. Because the steam into the steam turbine doesn't work, all been pumped out for heating and not a bit of it is discharged, so the back pressure $P_{b}$ of steam turbine is a minimum.

(2) When the electricity supply with cogeneration steam turbine is increased and the amount of heating is declined, the amount of heating is $Q_{1}$, the electricity supply is $Q_{2}$. Because the part of steam has been pumped out for heating is less and less when after working into the steam turbine, and it has been discharged is more and more, so the back pressure $P_{b}$ of steam turbine is bigger and bigger. 
(3) When the cogeneration steam turbine all electricity supply, without heating, at this time the electricity supply is $Q_{2}$. Because the steam into the steam turbine doesn't been pumped out for heating, all been discharged after working into the steam turbine, so the back pressure $P_{b}$ of steam turbine is a maximum.

Above all, a relationship can be deduced between thermoelectric ratio and back pressure as following.

$$
\begin{aligned}
& \frac{Q_{1}}{Q_{2}}=\frac{K_{1}}{P_{b}^{n}} \\
& \left(Q_{1}>0, Q_{2}>0, K_{1}>0, P_{b} \geq P_{c r}, n>0\right)
\end{aligned}
$$

$K_{1}$ as the scale coefficient, $n$ as the undetermined coefficient, $Q_{1}$ as the amount of heating, $Q_{2}$ as the electricity supply.

Relationship between back pressure and internal temperature and pressure of steam turbine. The internal temperature and pressure condition of steam turbine can be reflected by the changes of back pressure. The flow of steam at steam turbine outlet is more and smaller when the back pressure from big too small. Because the steam turbine is in the case of full load operation, so the steam into the steam turbine is unchanged. At this time the temperature and pressure near the inlet remain unchanged and near the outlet is gradually smaller [5].

A relationship can be deduced between back pressure and the temperature and pressure near the outlet of steam turbine as following.

$$
\begin{aligned}
& P_{b}=K_{2} T_{2}{ }^{n} \\
& P_{b}=K_{3} P_{2}{ }^{n} \\
& \left(K_{2}>0, K_{3}>0, P_{b} \geq P_{c r}, n>0\right)
\end{aligned}
$$

$K_{2}$ and $K_{3}$ as the scale coefficient, $n$ as the undetermined coefficient, $T_{2}$ as the temperature near the outlet, $P_{2}$ as the pressure near the outlet.

\section{Analysis of usual fault with steam turbine rotor}

In recent years, due to the heating area increased in winter, so the steam quantity has been pumped out for heating must often adjust according to the change of weather to ensure the quality of heating [6]. For the regulated extraction steam turbine, thermoelectric load ratio need to adjust according to the change of thermoelectric demand. This will make the back pressure changed from time to time and may affect the size and distribution of the temperature and pressure in steam turbine. Which will ultimately affect the working state of steam turbine, at the same time will have some impacts on the various possible fault.

The temperature and pressure in cylinder will be changed directly if the back pressure of steam turbine is changed, that will have an effect on the fault of steam turbine rotor in two aspects.

First, if the change of back pressure is large, make the temperature change inside the cylinder exceeds the normal range of rotor can bear, it will make the rotor serious thermal bending and have an effect on moderate of rotor. Make the rotor running out of balance, resulting in a series of problem, for example violent collision between the rotor and bearing.

Second, according to the distribution of steam turbine structure can be seen that if the back pressure changes will cause changes of the steam pressure at the outlet. But the steam pressure at the inlet remained unchanged, so the pressure differential of the rotor bear will changed and leads to the axial force of the rotor is changed. If the imbalance force exceeds the limit value, it will make the turbine rotor axial displacement, even will cause the rotor and stator have rubbed, aggravate the unit vibration, and even cause serious accident. 


\section{Effect of thermoelectric load changes}

Strain analysis of steam turbine stator. When the thermoelectric load of steam turbine changes, the temperature near the outlet $T_{2}$ changed and near the inlet $T_{1}$ remained unchanged. Then it will make the temperature distribution on the steam turbine along the steam flow direction change. Assume the front and back ends temperature differential of the stator is $\Delta T$, if the temperature differential $\Delta T$ change sharply, more than the capacity that stator can bear, will make the stator thermal expansion. So the relationship between the thermal expansion degree $\delta_{1}$ and thermoelectric ratio of stator can be deduced as following.

$$
\begin{aligned}
& \Delta T=T_{1}-T_{2} \\
& \delta_{1}=\frac{K_{T 1}}{\Delta T^{n}}=\frac{K_{T 1}}{\left(T_{1}-T_{2}\right)^{n}}=\frac{K_{T 1}}{\left(T_{1}-\frac{P_{b}}{K_{2}}\right)^{n}}=\frac{K_{T 1}}{\left(T_{1}-\frac{K_{1}}{K_{2}} \bullet \frac{Q_{2}}{Q_{1}}\right)^{n}} \\
& \left(T_{1}>T_{2}>0, K_{T 1}>0, n>0\right)
\end{aligned}
$$

$K_{T 1}$ as the scale coefficient, $n$ as the undetermined coefficient.

Strain analysis of steam turbine rotor. The same due to the thermoelectric load changes lead to the temperature near the outlet $T_{2}$ changed and near the inlet $T_{1}$ remained unchanged. Then it will make a temperature differential $\Delta T$ between front and back of the steam turbine rotor, if the temperature differential $\Delta T$ change sharply, more than the capacity that rotor can bear, will make the rotor thermal bending. So the relationship between the thermal bending degree $\delta_{2}$ and thermoelectric ratio of rotor can be deduced as following.

$$
\begin{aligned}
& \delta_{2}=\frac{K_{T 2}}{\Delta T^{n}}=\frac{K_{T 2}}{\left(T_{1}-T_{2}\right)^{n}}=\frac{K_{T 2}}{\left(T_{1}-\frac{P_{b}}{K_{2}}\right)^{n}}=\frac{K_{T 2}}{\left(T_{1}-\frac{K_{1}}{K_{2}} \bullet \frac{Q_{2}}{Q_{1}}\right)^{n}} \\
& \left(T_{1}>T_{2}>0, K_{T 2}>0, n>0\right)
\end{aligned}
$$

$K_{T 2}$ as the scale coefficient, $n$ as the undetermined coefficient.

Stress analysis of steam turbine rotor. Due to the steam turbine in the case of full load operation, the pressure near the inlet $P_{1}$ remained unchanged and the pressure near the outlet $P_{2}$ or back pressure $P_{b}$ near the outlet will change with the variation of the thermoelectric load. Then it will produce a pressure differential $\Delta P$ between front and back of the steam turbine rotor. Because the axial force on rotor is the sum of the axial force on moving blade, impeller and rotor shoulder, so the following will analyze the axial force size on the moving blade, impeller and rotor shoulder.

The axial thrust on the moving blade

$$
F_{a 1}=G\left(C_{1} \sin \alpha_{1}-C_{2} \sin \alpha_{2}\right)+\pi d_{b} l_{b}\left(P_{1}-P_{2}\right)
$$

Because $C_{1} \sin \alpha_{1} \approx C_{2} \sin \alpha_{2}$

$$
F_{a 1} \approx \pi d_{b} l_{b}\left(P_{1}-P_{2}\right)
$$

The axial thrust on the impeller

$$
F_{a 2}=\frac{\pi}{4}\left[\left(d_{b}-l_{b}\right)^{2}-d_{1}^{2}\right] \bullet P_{1}-\frac{\pi}{4}\left[\left(d_{b}-l_{b}\right)^{2}-d_{2}^{2}\right] \bullet P_{2}
$$

If the hub diameter on two sides of the impeller equal

$$
\begin{aligned}
& d_{1}=d_{2}=d \\
& F_{a 2}=\frac{\pi}{4}\left[\left(d_{b}-l_{b}\right)^{2}-d^{2}\right] \bullet\left(P_{1}-P_{2}\right)
\end{aligned}
$$

The axial thrust on the rotor shoulder 


$$
F_{a 3}=\frac{\pi}{4} \bullet\left(d_{1}^{2}-d_{2}^{2}\right) \bullet\left(P_{1}-P_{2}\right)
$$

So the total axial thrust on the rotor can be obtained

$$
F_{a}=F_{a 1}+F_{a 2}+F_{a 3}=\left\{\pi d_{b} l_{b}+\frac{\pi}{4}\left[\left(d_{b}-l_{b}\right)^{2}-d^{2}\right]+\frac{\pi}{4}\left(d_{1}^{2}-d_{2}^{2}\right)\right\} \bullet\left(P_{1}-P_{2}\right)
$$

If assume that

$$
\begin{aligned}
& K_{p}=\pi d_{b} l_{b}+\frac{\left.\pi \mid\left(d_{b}-l_{b}\right)^{2}-d^{2}+\left(d_{1}^{2}-d_{2}^{2}\right)\right]}{4} \\
& F_{a}=K_{p} \bullet\left(P_{1}-P_{2}\right)=K_{p} \bullet\left(P_{1}-\frac{P_{b}}{K_{3}}\right)=K_{p} \bullet\left(P_{1}-\frac{K_{1}}{K_{3}} \bullet \frac{Q_{2}}{Q_{1}}\right) \\
& \left(K_{P}>0\right) \\
& K_{P} \text { as the scale coefficient. }
\end{aligned}
$$

\section{Summary}

(1) The thermal expansion degree $\delta_{1}$ of steam turbine stator is inversely proportional to thermoelectric ratio $Q_{1} / Q_{2}$ of thermoelectric load. Thermoelectric ratio is smaller, the temperature differential $\Delta T$ along the steam flow direction inside the cylinder is smaller, temperature distribution of stator along the steam flow direction of each point is bigger, and the stator thermal expansion degree will be bigger. When $P_{b}=P_{c r}$, the thermal expansion is minimum.

(2) The thermal bending degree $\delta_{2}$ of steam turbine rotor is inversely proportional to thermoelectric ratio $Q_{1} / Q_{2}$ of thermoelectric load. Thermoelectric ratio is bigger, the temperature differential $\Delta T$ at the two ends of the rotor is bigger, and the rotor thermal bending degree will be smaller. When $P_{b}=P_{c r}$, the thermal bending is minimum.

(3) The axial thrust $F_{a}$ of steam turbine rotor is proportional to thermoelectric ratio $Q_{1} / Q_{2}$ of thermoelectric load. With the increase of thermoelectric ratio, the pressure differential $\Delta P$ between front and back of the steam turbine rotor is bigger. When $P_{b}=P_{c r}$, the $\Delta P$ and $F_{a}$ is maximum.

\section{References}

[1] W.J. Kearton, Steam turbine theory and practice: a textbook for engineering students. I. Pitman, 1948.

[2] C.Z. CHEN, Q. Li, Y.F. LIU and Y.G. WANG, "Intelligent fault diagnosis method for turbo-generator unit [J]." Proceedings of the CSEE 5 (2002): 023.

[3] D.G. Shepherd, Principles of turbomachinery. Macmillan, 1956.

[4] A. Bellini, F. Filippetti, C. Tassoni and G.A. Capolino, "Advances in diagnostic techniques for induction machines." Industrial Electronics, IEEE Transactions on 55.12 (2008): 4109-4126.

[5] A. Muszynska, "Vibrational diagnostics of rotating machinery malfunctions." International Journal of Rotating Machinery 1.3-4 (1995): 237-266.

[6] H. Suga, K. Sagawa and A.A. Shoukas, "Load independence of the instantaneous pressurevolume ratio of the canine left ventricle and effects of epinephrine and heart rate on the ratio." Circulation research 32.3 (1973): 314-322. 